\title{
Effect of microstructure and cooling rate on the fatigue performance of TIMETAL ${ }^{\circledR} 575$
}

\author{
M.Bodie $^{\mathrm{a},{ }^{*}, \text { M.Thomas }}{ }^{\mathrm{a}},{ }^{\text {A.Ayub }}{ }^{\mathrm{b}}$

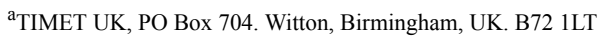 \\ ${ }^{\mathrm{b}}$ University of Hertfordshire, Hatfield AL10 9AB \\ *Michael.Bodie@timet.com
}

Keywords: TIMETAL ${ }^{\circledR} 575$, Fatigue, Cooling Rate, Mechanical Property Characterisation

\section{$\underline{\text { Abstract }}$}

A key design consideration for material selection in the aerospace industry is weight reduction; with excellent strength to weight ratio, high temperature resistance, and fatigue performance, titanium alloys are extensively used. New titanium alloys continue to enhance performance and broaden the range of applications. Titanium Metals Corporation (TIMET) recently developed TIMETAL ${ }^{\circledR} 575$ (Ti575), a high strength titanium alloy with superior fatigue performance over Ti-6Al-4V, aimed at aerospace applications where these properties are imperative i.e. aerospace turbine discs and blades. [1] [2]

This work intends to advance the understanding of the effect of thermal processing of Ti575, by investigating the effect of primary alpha ( $\left.\alpha_{\mathrm{p}}\right)$ volume fraction and cooling rate on tensile and fatigue performance in post forged heat-treated microstructures. Microstructural assessment and mechanical performance were completed and are discussed.

Three cooling methods from three solution heat-treat temperatures were investigated in this work. The results from these experiments were compared using optical microscopy, electron backscatter diffraction (EBSD), room temperature tensile and high cycle fatigue (HCF) tests.

\section{Introduction}

Cooling rate has a substantial impact on the microstructure of titanium alloys, altering the morphology and phase composition hence influencing properties. Continuous cooling transformation (CCT) phase diagrams are used to predict cooling rates influence on microstructures and aid in tailoring mechanical properties for a given application. For new development alloys such as Ti575, there is currently no literature or data available to construct a CCT diagram. This work aims to identify some key boundaries on a basic CCT diagram for Ti575 to determine temperatures at which microstructural features begin to form and ultimately be able to optimise processing parameters.

Alloys with higher $\beta$-phase stability coefficients result in transformations occurring at lower temperatures, and this leads to less diffusion of alloying elements to their respective phases. As a result, less diffusion of alpha stabilisers to secondary alpha $\left(\alpha_{s}\right)$ takes place during the $\beta \rightarrow \alpha+\beta$ transformation, producing a finer transformation product. Since more time is required to achieve the same microstructure, the transformation curve will be pushed to the right. As Ti575 has a higher $\beta$-phase stability coefficient than Ti-6Al-4V it is predicted that the boundaries identified by the CCT diagram will be further to the right.

In near alpha and alpha+beta titanium alloys, large regions of local texture, referred to as "macrozones", are capable or reducing the fatigue life of components when the fatigue cycle contains a dwell period at peak stress [5]. The local texture can be influenced by both morphological features of the bi-modal microstructure which are utilised for their good balance in fatigue and creep properties. The texture of $\alpha_{\mathrm{p}}$ evolves from coarse lamellae that undergoes dynamic spherodisation and recrystallisation mechanisms during thermal mechanical processing, while the texture of $\alpha_{\mathrm{s}}$ is inherited from the high temperature $\beta$-phase through the Burgers orientation relation and variant selection occurring in the $\beta \rightarrow \alpha$ transformation. $\alpha_{\mathrm{S}}$ have been known to have favourable variants which align their c-axis with those of neighbouring $\alpha_{p}$ [4] [5]. In this work, EBSD was undertaken to investigate the effect of $\alpha_{p}$ volume fraction and cooling rate on prior beta grain size and $\alpha_{\mathrm{s}}$ colony size.

Table 1. Nominal composition of Ti575 (wt\%)

\begin{tabular}{|c|c|c|c|c|c|}
\hline $\mathrm{Fe}$ & $\mathrm{V}$ & Si & $\mathrm{Al}$ & $\mathrm{O}$ & $\mathrm{Ti}$ \\
\hline 0.25 & 7.7 & 0.5 & 5.3 & 0.18 & $\mathrm{Bal}$ \\
\hline \multicolumn{6}{|c|}{ Table 2. Material data } \\
\hline Alloy & \multicolumn{3}{|c|}{ Density $\left(\mathrm{g} / \mathrm{cm}^{3}\right)$} & \multicolumn{2}{|c|}{ Beta Transus } \\
\hline Ti575 & \multicolumn{3}{|c|}{4.55} & \multicolumn{2}{|c|}{$967.5 \pm 5^{\circ} \mathrm{C}$} \\
\hline
\end{tabular}

\section{Experimental Procedure}

Material used in this experiment was sourced from a full-scale triple melted vacuum arc remelted (VAR) ingot of Ti575 manufactured by TIMET UK Witton plant. The ingot received a proprietary sequence of forging operations leading to a $250 \mathrm{~mm}$ diameter billet. Samples were sectioned from the forged billet into $20 \times 20 \times 120 \mathrm{~mm}$ test pieces.

Samples were held at three different solution heat treatment temperatures $\left(880^{\circ} \mathrm{C}, 910^{\circ} \mathrm{C}\right.$ and $\left.940^{\circ} \mathrm{C}\right)$ for 1 hour to provide varying proportions of $\alpha_{\mathrm{p}}$, and were then cooled using three different cooling mediums (vermiculite, air and oil). Depending on the solution heat treatment temperature and cooling medium, cooling rates varied from 2 to $16^{\circ} \mathrm{C} / \mathrm{s}$.

Cooling curves were measured using an embedded K-type thermocouple located in the centre of a test block which recieved each of the nine different cooling conditions. An example of the thermocouple traces from solution heat treatment at $940^{\circ} \mathrm{C}$ is shown in Figure 1. 


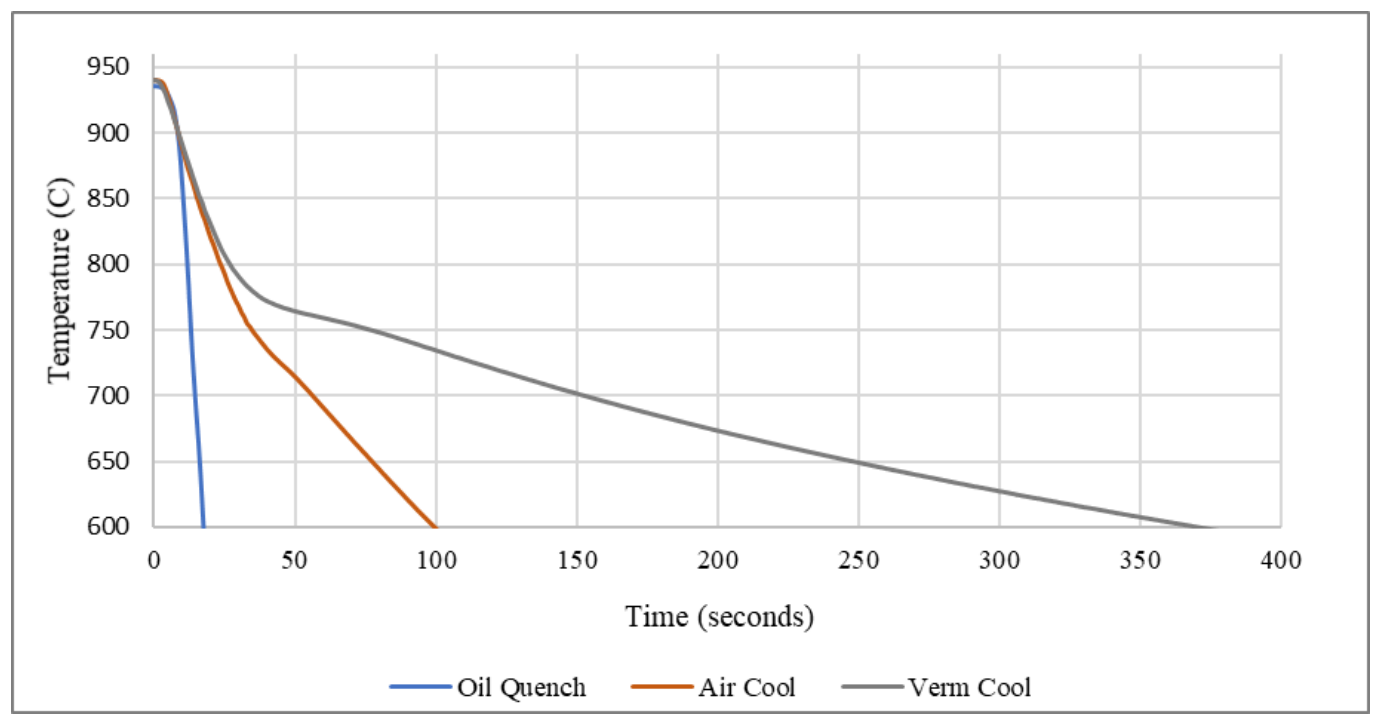

Figure 1. Thermocouple trace for different cooling mediums when cooling from $940^{\circ} \mathrm{C}$

The end of the dual phase field was identified as the temperature at which the cooling curve resumed a steady rate after the exothermic phase transformation when the test block was air cooled from $1065^{\circ} \mathrm{C}$. End of dual phase field is indicated on Figure 2 and Figure 3, established at $737^{\circ} \mathrm{C}$. Cooling rate was calculated by the difference in solution heat treat temperature and the end of dual phase field $\left(\mathrm{T}_{\beta}^{\mathrm{f}} \rightarrow \alpha+\beta\right)$ divided by time. The end of the dual phase field temperature varies with cooling rate since increased undercooling leads to the transformation temperature being suppressed. Due to experimental limitations this was assumed to be a fixed temperature when calculating cooling rates.

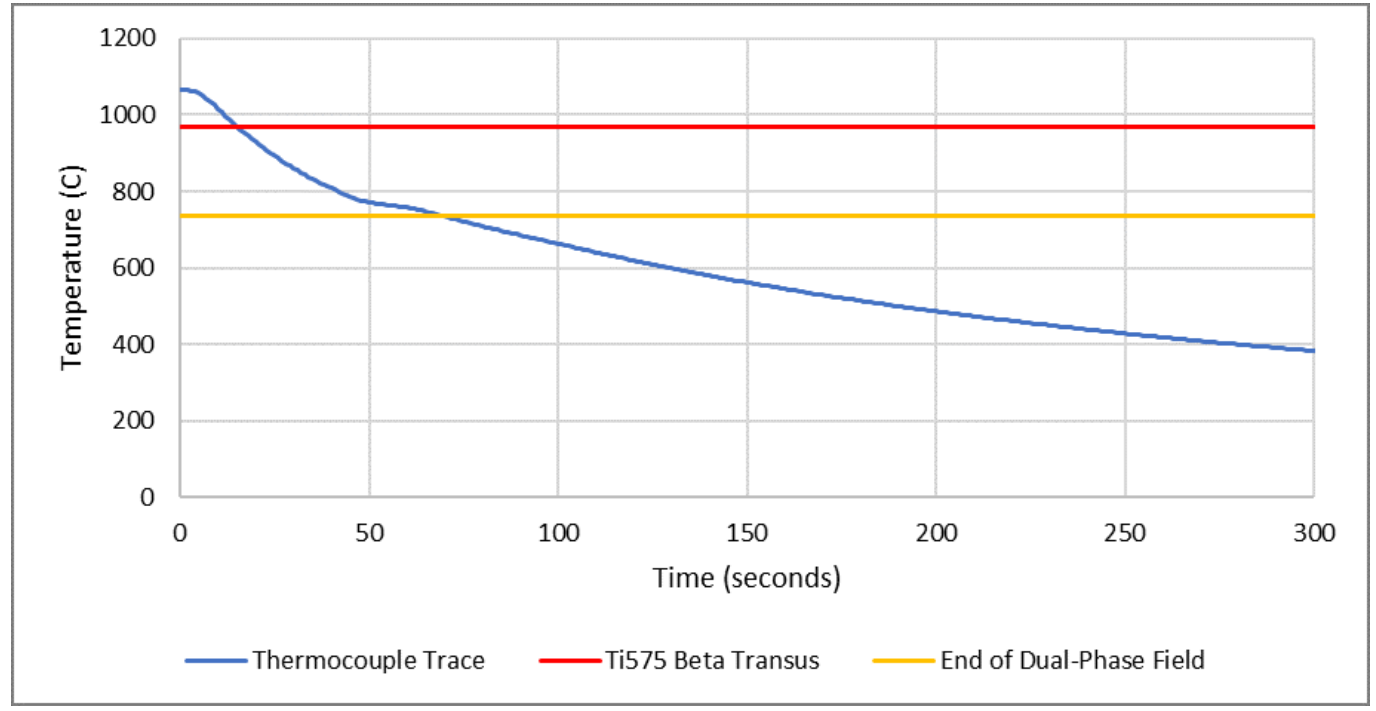

Figure 2. Thermocouple trace for air cooled Ti575 from $1065^{\circ} \mathrm{C}$

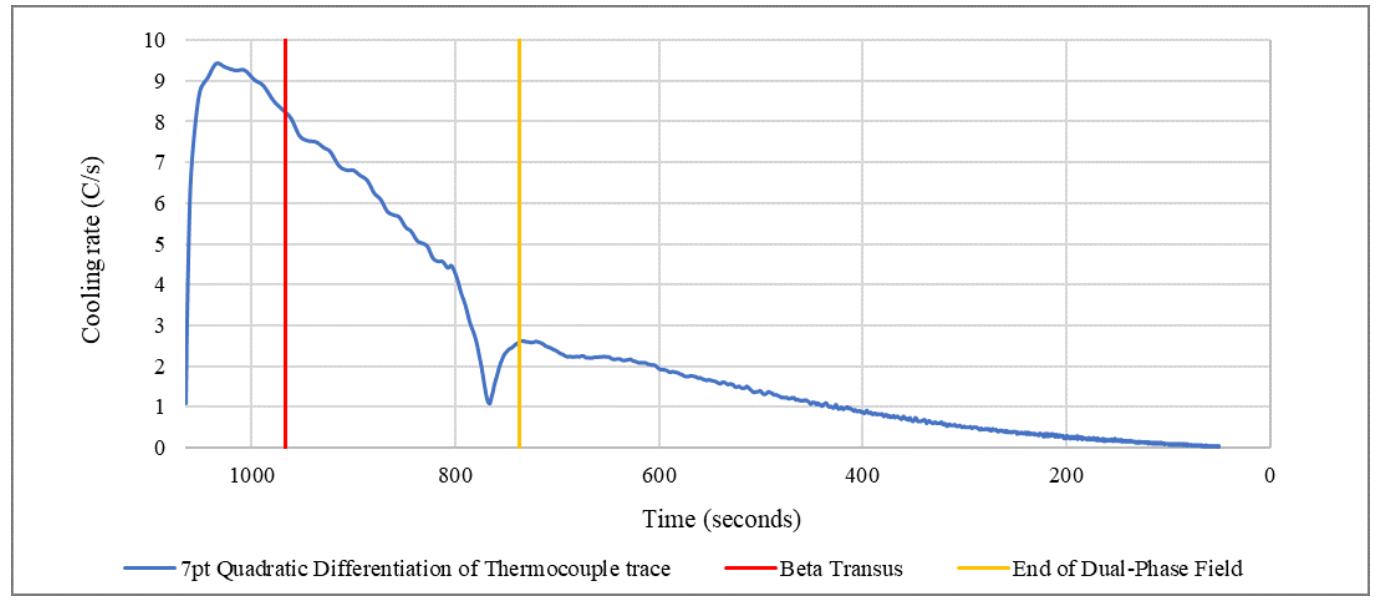

Figure 3. Cooling rate curve for air cooling Ti575 from $1065^{\circ} \mathrm{C}$ using $7 \mathrm{pt}$ Quadratic Differentiation

All samples received an aging treatment at $500^{\circ} \mathrm{C}$ for 8 hours before mechanical testing was completed.

Post heat-treated samples were machined into test pieces for tensile and HCF tests, which were carried out at TIMET Witton and Swansea University.

Dual rate tensile tests were completed under strain control using a strain rate of $0.003 \mathrm{~s}^{-1}$ up to yield followed by displacement control using a strain rate of $\leq 0.1 \mathrm{~s}^{-1}$ on to fracture. 
HCF were completed with $\sim 100 \mathrm{~Hz}$ sine wave on a vibrophore under load control and $\mathrm{R} \approx 0$. Tests were to be terminated if the test piece reached $2 \mathrm{x} 10^{7}$ cycles designated as the "run-out" condition however; no samples survived to run-out. All tests were carried out in accordance with BS EN 6072:2010 at a fixed peak stress of 700MPa. [2]

To establish when key microstructure features begin to form, 11 samples sectioned into $20 \times 20 \times 40 \mathrm{~mm}$ test pieces were heated in the beta phase $\left(1065^{\circ} \mathrm{C}\right)$ for 1 hour then air cooled to the temperatures listed in Table 3. Once the temperature in Table 3 was met, the samples were water quenched to "freeze in" the microstructural features at that temperature. The microstructure from each condition was then characterised to establish boundaries on a basic CCT diagram. Temperatures in Table 3 were determined using a test block with embedded thermocouple as before.

Table 3. Air cooled temperatures interrupted with water quench

\begin{tabular}{||c||c||}
\hline \multicolumn{2}{|c|}{ Start temperature $1065^{\circ} \mathrm{C}$} \\
\hline \hline Temperature $\left({ }^{\circ} \mathrm{C}\right)$ & Air Cool Time (secs) \\
\hline 1000 & 12 \\
\hline 970 & 15 \\
\hline 940 & 19 \\
\hline 910 & 23 \\
\hline \hline 880 & 27 \\
\hline \hline 850 & 32 \\
\hline \hline 820 & 38 \\
\hline \hline 790 & 44 \\
\hline \hline 760 & 58 \\
\hline \hline 730 & 72 \\
\hline 700 & 84 \\
\hline \hline
\end{tabular}

High resolution EBSD maps $\sim 1$ x $0.75 \mathrm{~mm}$ with a $0.2 \mu \mathrm{m}$ step size were generated at TIMET Witton on an FEI Quanta FEG250 equipped with an HKL Channel 5 system. EBSD maps were generated on all samples cooled from $940^{\circ} \mathrm{C}$ along with samples air cooled from $910^{\circ} \mathrm{C}$ and $880^{\circ} \mathrm{C}$.

\section{Results and Discussion}

\section{Microstructure}

Since all non-interrupted cooling rates experiments were carried out in the dual phase field, bimodal microstructures were observed with varying proportions of $\alpha_{\mathrm{p}}$ based on the solution heat treat temperature. Cooling Ti575 at the rate of $8.37^{\circ} \mathrm{C} / \mathrm{s}$ or faster resulted in the development of a martensitic microstructure seen in Figure $4 \mathrm{a}$, made up of $\alpha_{\mathrm{p}}$ and $\alpha^{\prime}$ with no grain boundary alpha forming. The formation of martensite was confirmed using high magnification backscattered imaging seen in Figure 4d.

For cooling rates between 5.12 and $4.77^{\circ} \mathrm{C} / \mathrm{s}$, some diffusional transformations begin to take place and a basketweave morphology is observed along with grain boundary alpha situated on prior beta grain boundaries, as represented in Figure $4 \mathrm{~b}$.

During slower cooling rates, between 2.10 and $3.22^{\circ} \mathrm{C} / \mathrm{s}$, diffusion controlled nucleation and growth of stable $\alpha$ and $\beta$ phases in colonies of aligned $\alpha$-phase lamellae within prior $\beta$-phase grains was observed. Significant amounts of grain boundary alpha formation can also be seen, Figure 4c. [3]

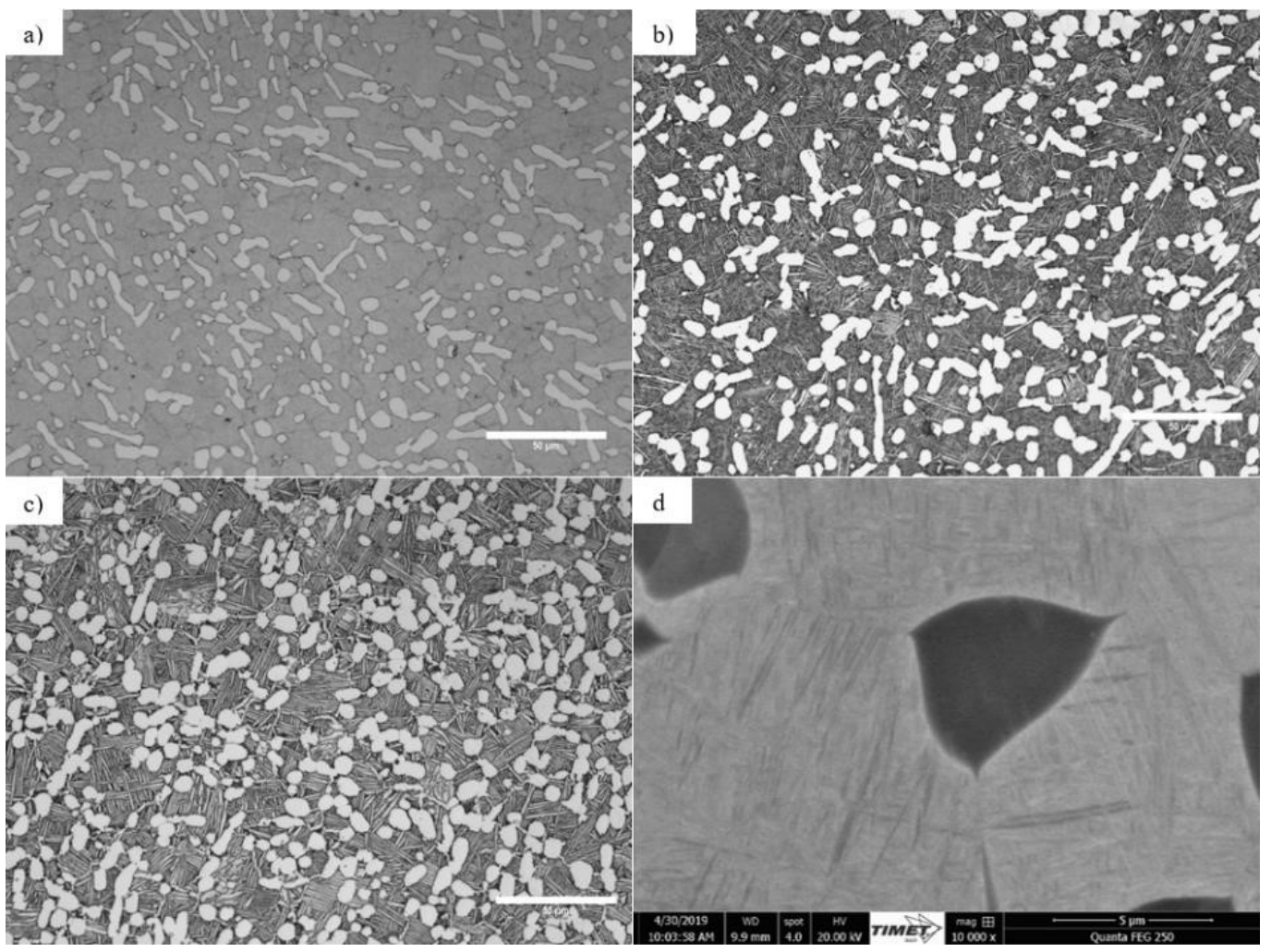

Figure 4. Optical micrograph of Ti575 SHT at $880^{\circ} \mathrm{C}$ with a) oil quenched $\left(10.94^{\circ} \mathrm{C} / \mathrm{s}\right.$ cooling rate) b) air-cooled $\left(4.90^{\circ} \mathrm{C} / \mathrm{s}\right.$ cooling rate) $\left.\mathrm{c}\right)$ vermiculite cooled $\left(3.22^{\circ} \mathrm{C} / \mathrm{s}\right.$ cooling rate) d) Backscattered SEM image of martensite formed. 
Samples air cooled then water quenched at $30^{\circ} \mathrm{C}$ intervals are shown on the basic CCT diagram in Figure 5. Within the temperature range of $1000-940^{\circ} \mathrm{C}$, a fully martensitic microstructure is formed with no grain boundary alpha. Between $910-880^{\circ} \mathrm{C}$, non-continuous alpha begins to form on the prior beta grain boundary. This alpha continues to grow forming continuous grain boundary alpha at $850^{\circ} \mathrm{C}$. At $820^{\circ} \mathrm{C}, \alpha_{\mathrm{s}}$ begins to nucleate and grow off the grain boundary alpha as colonies of $\alpha_{\mathrm{s}}$. By $790^{\circ} \mathrm{C}$, there are increased amounts of $\alpha_{\mathrm{s}}$ growing from the grain boundary along with some $\alpha_{\mathrm{S}}$ beginning to form within the beta grain in a basketweave morphology. Both $\alpha_{\mathrm{S}}$ colonies from the grain boundary and $\alpha_{\mathrm{S}}$ within beta grains form at $760^{\circ} \mathrm{C}$. At $730^{\circ} \mathrm{C}$ the $\alpha_{\mathrm{s}}$ lamellae have begun to coarsen and by $700^{\circ} \mathrm{C}$ aligned alpha colonies have formed.

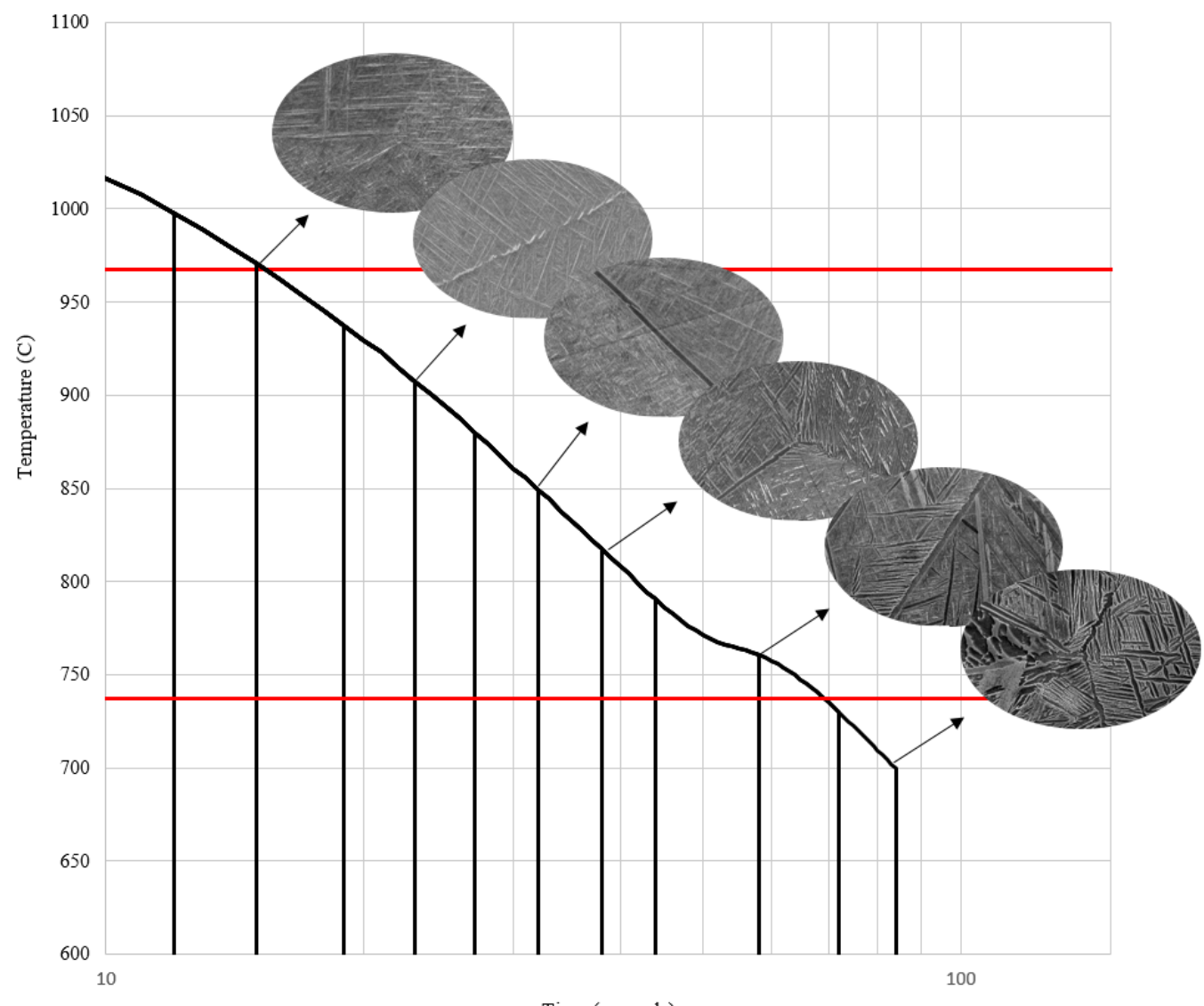

Time (seconds)

Figure 5. Ti575 air cooled from $1065^{\circ} \mathrm{C}$ interrupted at $30^{\circ} \mathrm{C}$ intervals with water quench

Tensile

Table 4. Tensile results in the solution heat treated and aged condition

\begin{tabular}{|c|c|c|c|c|c|c|}
\hline \multirow[b]{2}{*}{ Sample ID } & \multicolumn{2}{|c|}{$\mathrm{MPa}$} & \multicolumn{3}{|c|}{$\%$} & \multirow[b]{2}{*}{ Cooling rate $\left({ }^{\circ} \mathrm{C} / \mathrm{s}\right)$} \\
\hline & $0.2 \%$ P.S. & U.T.S & Elong ${ }^{\text {n. }}$ on $5.65 \sqrt{ } \mathrm{A}$ & Elong $^{\mathrm{n}}$. on $4 \mathrm{D}$ & R. in A. & \\
\hline $940^{\circ} \mathrm{C}$ OQ & 1305 & 1447 & 5.0 & 5.5 & $*$ & 15.69 \\
\hline $940^{\circ} \mathrm{C} \mathrm{AC}$ & 1049 & 1211 & 14.5 & 16.5 & 31.0 & 5.12 \\
\hline $940^{\circ} \mathrm{C} \mathrm{VC}$ & 975 & 1146 & 14.5 & 17.0 & 36.5 & 2.10 \\
\hline $910^{\circ} \mathrm{C}$ OQ & 1337 & 1468 & 8.5 & 9.5 & 27.0 & 8.37 \\
\hline $910^{\circ} \mathrm{C} \mathrm{VC}$ & 991 & 1128 & 15.5 & 18.0 & 39.0 & 2.66 \\
\hline $880^{\circ} \mathrm{C} \mathrm{OQ}$ & 1336 & 1455 & 11.0 & 12.5 & 34.0 & 10.94 \\
\hline $880^{\circ} \mathrm{C}$ AC & 1057 & 1182 & 16.5 & 19.5 & 46.0 & 4.90 \\
\hline $880^{\circ} \mathrm{C} \mathrm{VC}$ & 1018 & 1129 & 16.5 & 19.0 & 43.5 & 3.22 \\
\hline
\end{tabular}

*Unable to measure RinA due to a section missing post fracture

Variability can be seen in the calculated cooling rates in Table 4, these are due to the differing temperature range used in the calculation and the sensitivity of the equipment to measure change in temperature at faster cooling rates.

Table 5. Volume fractions of $\alpha_{p}$

\begin{tabular}{|c|c|c|c|}
\hline & $940^{\circ} \mathrm{C}$ & $910^{\circ} \mathrm{C}$ & $880^{\circ} \mathrm{C}$ \\
\hline \hline Oil Quench & $4 \%$ & $12 \%$ & $25 \%$ \\
\hline \hline Air Cool & $7 \%$ & $20 \%$ & $29 \%$ \\
\hline Vermiculite Cool & $8 \%$ & $22 \%$ & $37 \%$ \\
\hline
\end{tabular}

With decreasing cooling rate, the $\alpha_{\mathrm{p}}$ volume fraction increased as grains coarsened and alpha stabilising elements had more time to partition to $\alpha_{\mathrm{p}}$ grains, seen in Figure 6 . 


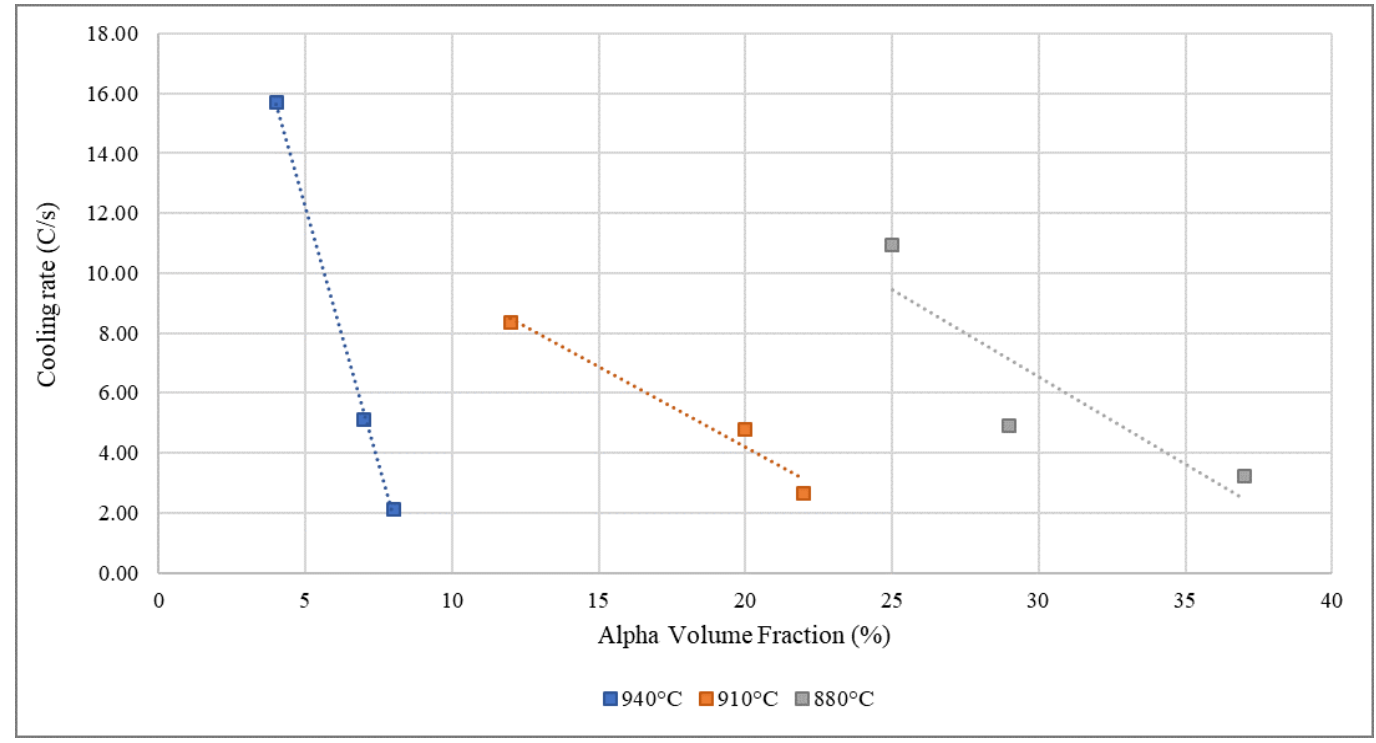

Figure 6. Effect of cooling rate on primary alpha volume fraction

No strong relationships were observed between the volume fraction of $\alpha_{\mathrm{p}}$ and tensile strength for any of the cooling mediums, seen in Figure 7 . This suggests that the base chemistry and the morphology of the higher volume fraction transformation product provides the primary impact on tensile properties rather than $\alpha_{\mathrm{p}}$ content in this alloy as illustrated by differences between cooling medium.

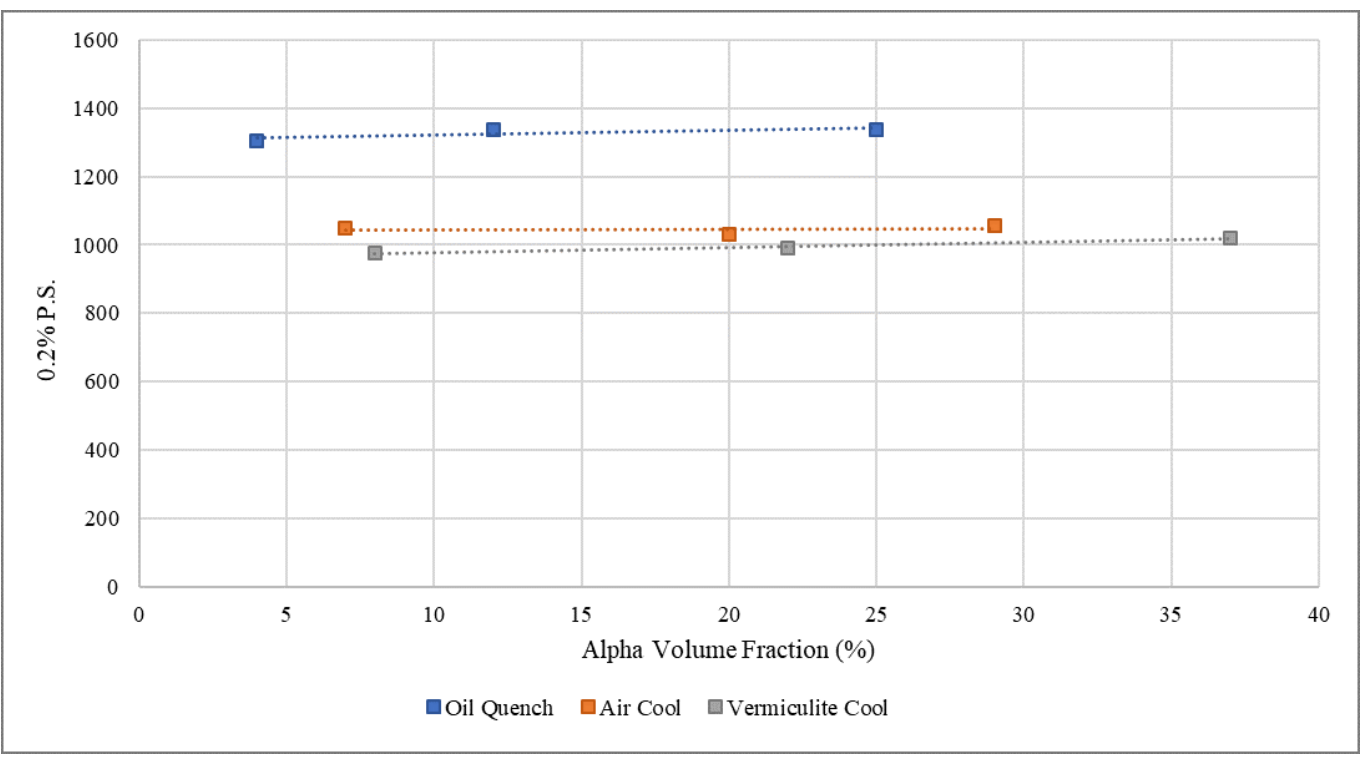

Figure 7. Effect of primary alpha volume fraction on proof strength of Ti575

Table 5. HCF results in the solution heat treated and aged condition. $880^{\circ} \mathrm{C} \mathrm{VermC}$ was omitted due to fracture location in the thread.

\begin{tabular}{|c|c|c|c|}
\hline Specimen Identity & Achieved Frequency $(\mathrm{Hz})$ & Cycles Completed & Fracture Location \\
\hline $880^{\circ} \mathrm{C}$ OQ & 106 & 4626960 & $\mathrm{~A}-\operatorname{mid} 1 / 3$ \\
\hline $880^{\circ} \mathrm{C} \mathrm{AC}$ & 106 & 8330725 & A - mid $1 / 3$ \\
\hline $910^{\circ} \mathrm{C}$ OQ & 106 & 6696087 & A - mid $1 / 3$ \\
\hline $910^{\circ} \mathrm{C} \mathrm{AC}$ & 106 & 7631276 & B - outer 1/3 (top) \\
\hline $910^{\circ} \mathrm{C}$ VermC & 105 & 5553646 & B - outer 1/3 (top) \\
\hline $940^{\circ} \mathrm{C}$ OQ & 106 & 6545598 & B - outer $1 / 3$ (bottom) \\
\hline $940^{\circ} \mathrm{C} \mathrm{AC}$ & 107 & 4019967 & B - outer 1/3 (top) \\
\hline $940^{\circ} \mathrm{C}$ VermC & 106 & 1593800 & B - outer $1 / 3$ (bottom) \\
\hline
\end{tabular}




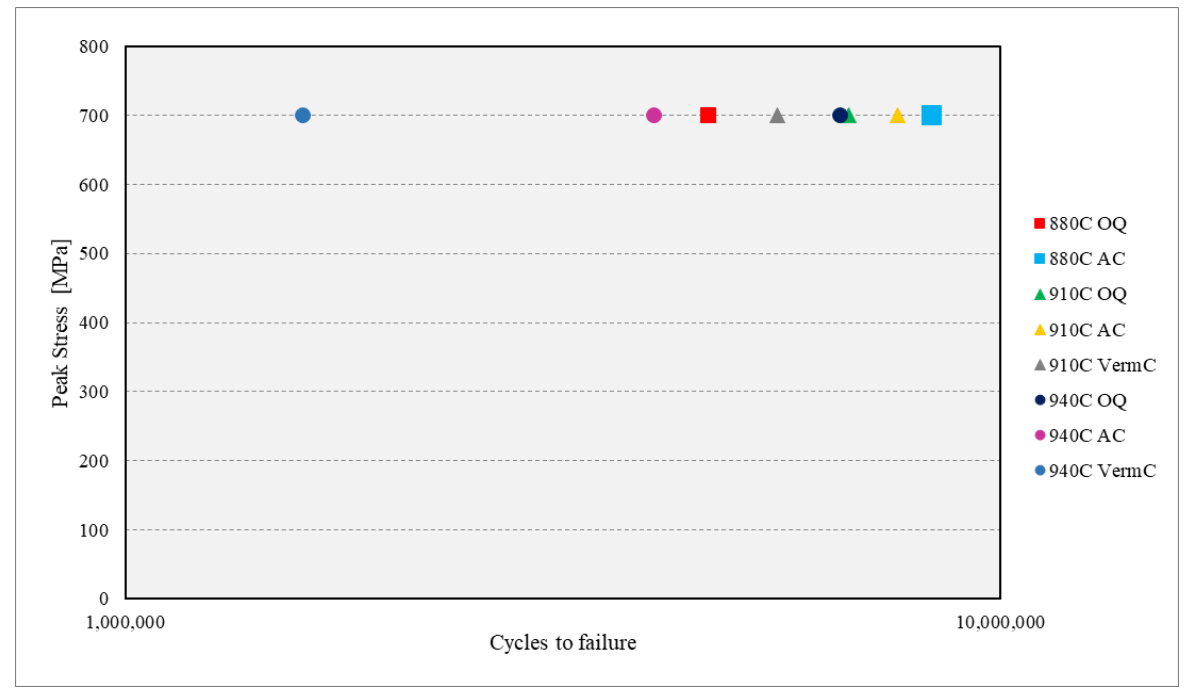

Figure 8. Peak Stress vs Cycles to Failure for Ti575 tested at room temperature, $\mathrm{R}=\mathbf{0}, \sim 100 \mathrm{~Hz}$ Sinusoidal Waveform

The sample solution heat treated at $880^{\circ} \mathrm{C}$ and vermiculite cooled fracture in the thread during HCF testing and this data point was excluded. Figure 9 indicates that as the $\alpha_{\mathrm{p}}$ volume fraction increased the number of cycles to failure increased for both the air and vermiculite cooled tests. This is explained in more detail in the EBSD section. However, for the oil quenched sample this was not the case showing a drop in the number of cycles to failure at larger volume fractions of $\alpha_{\mathrm{p}}$. This could be related to the change in morphology associated with oil quenching and the high dislocation density of martensite providing more strength than $\alpha_{\mathfrak{p}}$ grains therefore, the lower volume fraction $\alpha_{\mathrm{p}}$ in this microstructural condition provided better HCF results. Wu et al [6] found that in bi-modal Ti-6Al-4V microstructures $\alpha_{p}$ volume fractions between $30-50 \%$ provided the best fatigue performance which agreed with the trend seen for air and vermiculite cooled tests. Repeat testing to provide additional data points are necessary to confirm the trends in the HCF data as variability between tests are common.

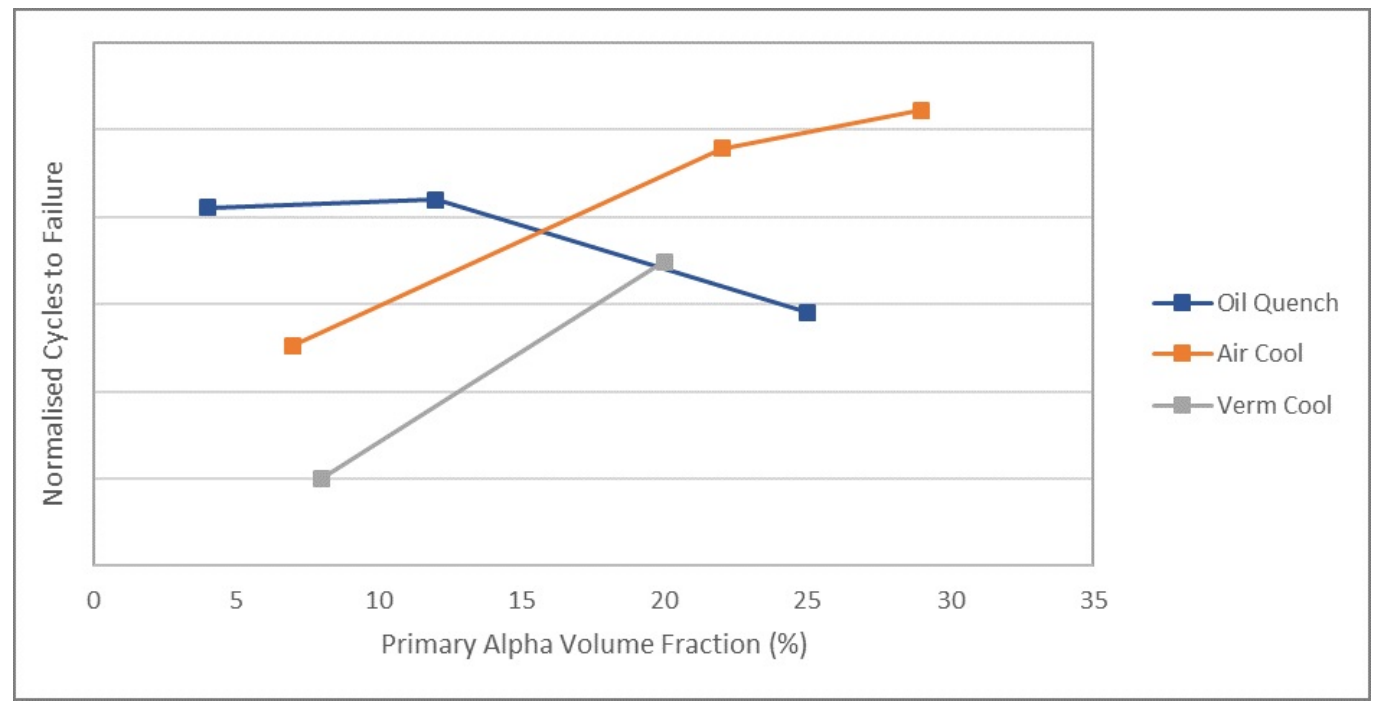

Figure 9. $\alpha_{\mathrm{p}}$ Volume Fraction vs Cycles to Failure for Ti575 cooled using different mediums

EBSD

Previous work carried out by Gey et al [4] determined that after transformation there are 5 misorientation types possible for variants within the same parent beta grain. By comparing misorientation of neighbouring pixels with theoretical misorientations, prior beta grain boundaries and $\alpha_{\mathrm{s}}$ colonies can be determined. In Figure 10, white lines denote the misorientations of adjacent pixels which match theoretical values (indicating $\alpha_{\mathrm{s}}$ colony sizes) and black lines denote any other misorientation provided their misorientation angles are higher than $3^{\circ}$ (indicating grain boundaries).

At higher volume fractions of $\alpha_{\mathrm{p}}$, smaller prior beta grains were observed, due to an increase in grain boundary pinning. This reduced grain size did not have a strong impact on tensile strength but appeared to reduce the number of cycles to failure during HCF.

Faster cooling rates resulted in smaller $\alpha_{\mathrm{S}}$ colony sizes which increased the tensile strength due to an increase in dislocation density. Slower cooling rates led to coarser lathes with increased local texture which might have contributed to reduction of cycles to failure observed for air and vermiculite cooled samples during HCF testing.

Larger prior beta grain size (seen at lower $\alpha_{\mathrm{p}}$ volume fractions) led to larger $\alpha_{\mathrm{s}}$ colonies, which in turn caused larger areas of local texture. This increased texture again might have contributed to the decrease in number of cycles to failure observed for air and vermiculite cooled samples during HCF testing. 



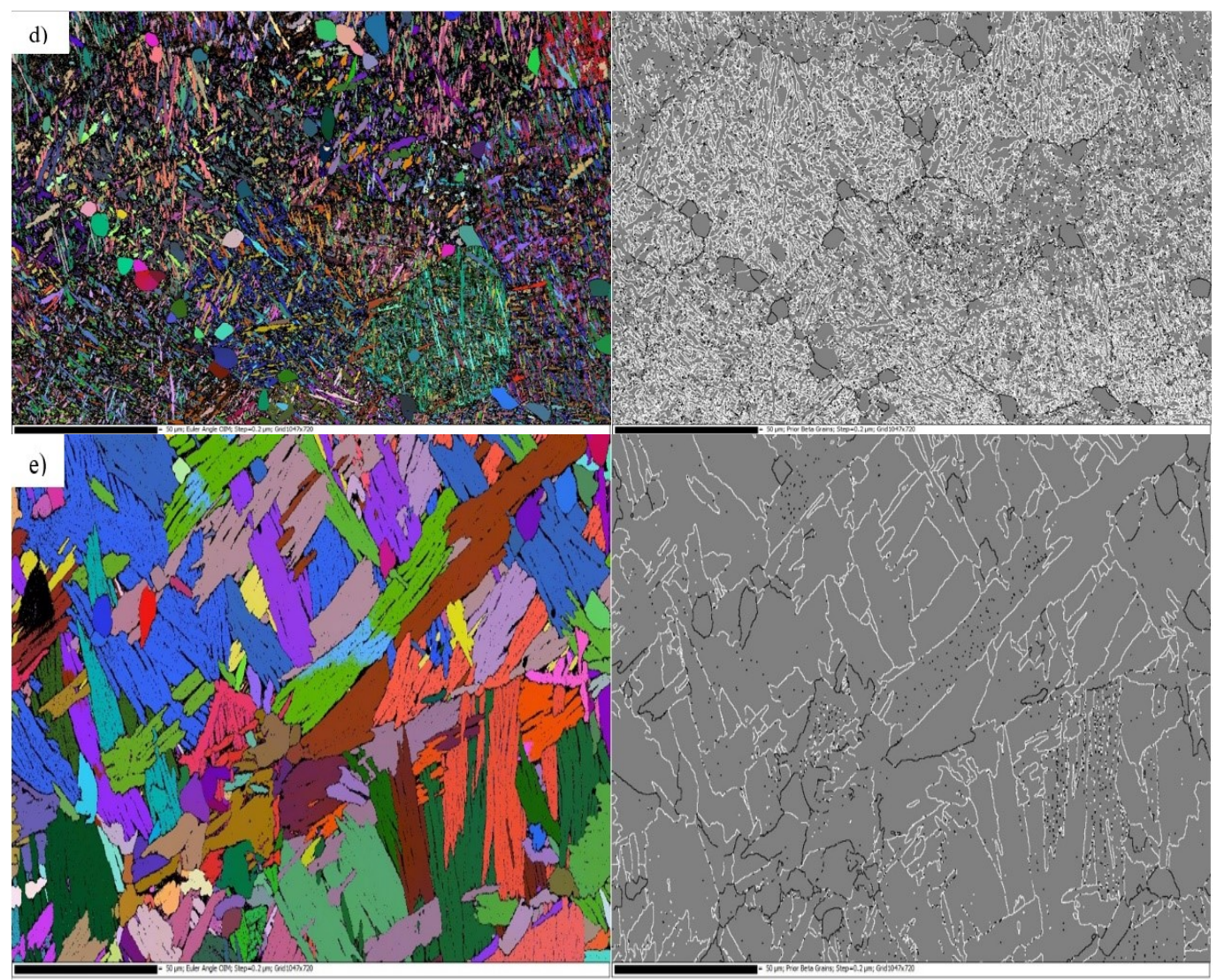

Figure 10. High resolution EBSD maps and prior beta grain boundaries for Ti575 SHT at a) $880^{\circ} \mathrm{C}$ and air cooled b) $910^{\circ} \mathrm{C}$ and air cooled c) $940^{\circ} \mathrm{C}$ and air cooled d) $940^{\circ} \mathrm{C}$ and oil quenched e) $940^{\circ} \mathrm{C}$ and vermiculite cooled

\section{Conclusions}

In this work, the cooling rates required to form martensitic, basketweave and aligned $\alpha_{\mathrm{s}}$ morphologies for Ti575 were established along with the temperature ranges in which key microstructural features begin to form when air cooling from the $\beta$ phase.

The base chemistry and the morphology of the higher volume fraction transformation product appeared to provide the primary impact on tensile properties rather than $\alpha_{\mathfrak{p}}$ content in this alloy. With increasing $\alpha_{p}$ volume fraction the number of cycles to failure during HCF for air and vermiculite cooled samples increased. However, a drop in the number of cycles to failure during HCF for the oil quenched test at high volume fraction of $\alpha_{\mathrm{p}}$ was observed, this is believed to be related to the change in morphology of the transformation product.

Faster cooling rates lead to changes in morphology with smaller $\alpha_{\mathrm{s}}$ colonies which increased the tensile strength.

EBSD showed that lower volume fraction of $\alpha_{\mathrm{p}}$ and slower cooling rates led to larger coarser $\alpha_{\mathrm{S}}$ colonies which in turn lead to larger textured regions which might be contributing to a reduction in the number of cycles to failure during HCF testing.

\section{Further Work}

Repeat HCF testing for sample excluded for fracturing in the thread, duplicate testing to confirm trends in HCF data and to determine whether high $\alpha_{\mathrm{p}}$ volume fraction oil quench test was an anomaly.

Separate $\alpha_{\mathrm{p}}$ and $\alpha_{\mathrm{s}}$ pole figures on EBSD maps to determine whether $\alpha_{\mathrm{s}}$ which grow from $\alpha_{\mathrm{p}}$ grains share similar orientation to help identify a link between $\alpha_{\mathrm{s}}$ variants aligning their c-axis with $\alpha_{\mathrm{p}}$.

\section{References}

[1] Rugg et al, "Effective structural unit size in titanium alloys," Journal of Strain analysis, Vol. 42, 2007.

[2] Thomas et al. "TIMETAL 575: A Novel High Strength Forgeable $\alpha / \beta$ Titanium Alloy," Conference proceedings of the $13^{\text {th }}$ World titanium Conference, 2016.

[3] Sieniawski et al, "Microstructure and Mechanical Properties of High Strength Two-Phase Titanium Alloys,” Titanium Alloys - Advances in Properties Control, Chapter 4, 2013.

[4] Gey et al, "Specific analysis of EBSD data to study the texture inheritance due to the $\beta \rightarrow \alpha$ phase transformation," Journal of materials science, Vol 38, Issue 6, 1289-1294, 2003.

[5] L.Germain et al, " $\beta \rightarrow \alpha_{\mathrm{S}}$ variant selection in sharp hcp textured regions of a bimodal IMI834 billet," Textures of materials, Proceedings of the $14^{\text {th }}$ International Conference of Textures of Materials, 2005.

[6] Wu et al, "Effect of microstructure on the fatigue properties of Ti-6Al-4V titanium alloys," Materials and Design, Vol 46, 668-674, 2013. 